\title{
Effect of Formaldehyde on Cardiorespiratory parameters in Medical students - An observational study
}

\author{
V Ravi Kumar ${ }^{1}$, M.C. Sudhakaran ${ }^{* 2}$, Ashwani Sharma ${ }^{3}$, Shivakrishna Gouroju 4. \\ ${ }^{1}$ Tutor, Department of Physiology, Andaman \& Nicobar Islands Institute of Medical Sciences, Port \\ Blair. South Andaman, India.
}

${ }^{* 2}$ Associate Professor, Department of Physiology, Govt. Medical College Thrissur, Kerala, India.

${ }^{3}$ Tutor, Department of Physiology, Andaman \& Nicobar Islands Institute of Medical Sciences, Port Blair. South Andaman, India.

${ }^{4}$ Assistant Professor, Department of Biochemistry, Andaman \& Nicobar Islands Institute of Medical Sciences, Port Blair. South Andaman, India.

\section{ABSTRACT}

Formaldehyde is extensively and commonly used in Department of Anatomy for preservation of biological specimens as well as cadavers. Formaldehyde being a noxious chemical, may cause respiratory health problems among $1^{\text {st }}$ year medical students attending dissection periodically as a part of MBBS curriculum. The following study was planned to observe the effect of formaldehyde vapours on heart rate, blood pressure, percentage oxygen saturation $\left(\mathrm{SpO}_{2}\right)$ and respiratory rate of $1^{\text {st }}$ year medical students who are routinely exposed to formalin vapours periodically. Randomly selected fifty medical students [Mean (SD) age of 18.94 (0.65) years] were assessed within 1week of admission to college and re-examined at intervals of 1 month and 6 months. Data was entered in Microsoft Excel and was analysed using Epi Info software version 7. There was a decrease in heart rate, systolic blood pressure, $\mathrm{SpO}_{2}$ values and respiratory rate (on comparing values after 6 months with that of baseline values) but it was not statistically significant. But it may be statistically significate after 1 year of periodical exposure and it could also be due to lower quantity of formalin exposure owing to the proper ventilation of the dissection hall as per the $\mathrm{MCl}$ regulations.

KEY WORDS: Formaldehyde, heat rate, blood pressure, $\mathrm{SpO}_{2}$, respiratory rate.

Address for correspondence: Dr. M.C. Sudhakaran, Associate Professor, Department of Physiology, Govt. Medical College Thrissur, Kerala, India. Phone:9933272165, E-Mail: ravik1691@gmail.com.

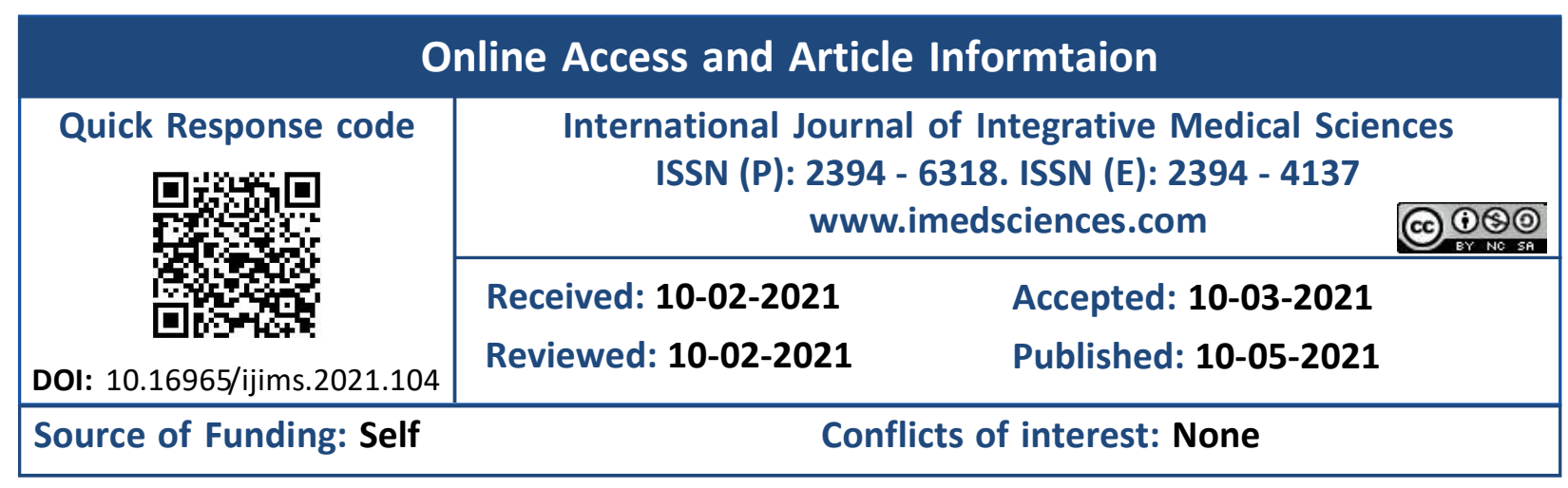

\section{INTRODUCTION}

Formalin solution contains $37 \%$ by weight or $40 \%$ by volume formaldehyde gas in water [1]. Formaldehyde being highly volatile and irritative in nature causes various adverse effects. Acute adverse effects include irritation and watering of eyes, nose and throat, in susceptible individuals causes laryngitis, asthmatic attacks, pain and bronchitis [2]. Squamous cell carcinoma of nasal respiratory epithelium in rats and mice are also seen [3].
Because of toxic effect of formaldehyde several European countries have restricted the use of formaldehyde (including the import of formaldehyde treated products and embalming) [4]. But in India we still use formaldehyde extensively in medical profession for purposes like embalming, external tissue fixation and thereby exposing medical professionals to this chemical.

Formaldehyde is extensively and commonly used in Department of Anatomy for preserva- 
tion of biological specimens as well as cadavers. In MBBS curriculum, time allotted in anatomy for dissection is $3 \mathrm{hrs}$ per day for 5 days a week. In this time slot all the $1^{\text {st }}$ year students are equally exposed to formaldehyde saturated environment in the dissection hall. Since, formaldehyde has adverse effect on exposure, in this study we aim to compare the effect of formaldehyde vapours on heart rate, systolic and diastolic blood pressure, $\mathrm{SpO}_{2}$ and respiratory rate among $1^{\text {st }}$ year medical students.

\section{METHODOLOGY}

Study was started after obtaining ethical committee clearance from IEC of Government Medical College, Thrissur. It was an observational prospective study which was conducted in department of Physiology, Government Medical College, Thrissur. A total of 100 students participated in this study by giving willingness. Out of 100 students $501^{\text {st }}$ year MBBS students (randomly selected, exposed to formaldehyde saturated environment as exposed group) and 50 nursing and paramedical students (randomly selected, not exposed to formaldehyde saturated environment as nonexposed group.) were selected. All these students were non-smokers, non-tobacco chewers and the age group between 17 and 20 years. Participants with having history of chronic respiratory disease, cardiac disease, previous exposure to formalin and examination finding suggestive of abnormal cardiac or respiratory disease were not included in this study.

The sample size was calculated based on study by Shrivastava A and Saxena $Y$ in 2013[5] using the formula with a power of study of $90 \%$ and significance level of $5 \%$, the sample size was calculated to be 100 (includes 50 exposed subjects and 50 non-exposed subjects)

$$
\left.n=\underline{\left(Z_{\alpha / 2}\right.}+\underline{Z}_{B}\right)^{2}\left(\sigma_{1}^{2}+\sigma_{2}^{2}\right)
$$

$$
\begin{aligned}
& \quad \mathbf{L}^{2} \\
& \text { Here } Z \alpha / 2=1.96 ; \quad \sigma 1=0.87 ; \sigma 2=0.8 . \\
& Z \beta=0.84 ; L=\text { mean } 1-\text { mean2 = 3.41 - 2.94; }
\end{aligned}
$$

Personal data of the subjects (name, age, sex) was noted. Detailed history of subjects were taken and respiratory $\&$ cardiovascular system examination was done to rule out any pre-existing respiratory or cardiovascular illness. Heart rate was recorded. Participant was seated comfortably. Mercury sphygmomanometer was kept at the level of heart. Cuff of appropriate size was tied around the right arm covering $2 / 3^{\text {rd }}$ of the arm about $2-3 \mathrm{~cm}$ above the cubital fossa. Blood pressure was measured using mercury manometer by palpatory and auscultatory method in right arm in sitting position. Systolic blood pressure (SBP) and diastolic blood pressure (DBP) were noted. Blood pressure measurements of the study participants were repeated at an interval of 1 minute. Three readings were taken and its mean value was noted. Respiratory rate (RR) was noted. Percentage oxygen saturation $\left(\mathrm{SpO}_{2}\right)$ was recorded using by pulse-oximeter. Readings were taken on three separate occasions. Baseline reading (first reading) was taken before MBBS students were taken to the dissection room i.e. pre-exposure reading. Second and third readings were repeated one month and six months after the start of dissection i.e. post-exposure readings. Same procedure was done for nursing and para-medical students. Data was entered in Microsoft Excel and was analysed using Epi Info software version 7. Statistical analysis was done using independent t-test and Paired t-test, for which, $p$-value $<0.05$ was taken as significant.

\section{RESULTS}

The study included 100 subjects of which 50 were males and 50 were females. The subjects were grouped into two categories based upon exposure to formalin. So, 25 males and females were in category that was exposed to formalin and 25 males and females were in category of non-exposed to formalin. Subjects were in the age group of 17 to 20 years (mean age $18.94 \pm 0.649$ ), height ranged from 149 to 191 $\mathrm{cm}$ (mean height $166.35 \pm 8.374$ ) and weight ranged from 37 to $95 \mathrm{~kg}$ (mean weight $59.36 \pm 11.224)$.

On evaluating the mean heart rate value of the exposed group in table 2 and on comparing the difference in mean heart rate in baseline reading and after six months among the two groups in table 3 , there was a gradual 
Table 2: Comparing the variables among MBBS (exposed) students.

\begin{tabular}{lcccc}
\hline & Mean & $\begin{array}{c}\text { Std. } \\
\text { deviation }\end{array}$ & t-value & Sig. (p value) \\
\hline HR (1)-HR (2) & 0.216 & 9.7 & 0.159 & 0.875 \\
HR (2)-HR (3) & $0 . .39$ & 11.375 & 0.025 & 0.98 \\
\hline HR (1)-HR (3) & 0.255 & 10.792 & 0.169 & 0.867 \\
\hline SBP (1)-SBP (2) & 2.4 & 10.917 & 1.554 & 0.127 \\
SBP (1)-SBP (3) & 2.96 & 10.382 & 2.016 & 0.062 \\
\hline SBP (2)-SBP (3) & 0.56 & 1.791 & 0.313 & 0.756 \\
\hline DBP (1)-DBP (2) & -1.76 & 8.65 & -1.44 & 0.16 \\
\hline DBP (1)-DBP (3) & -1.36 & 9.66 & -0.97 & 0.32 \\
DBP (2)-DBP (3) & 0.4 & 9.36 & 0.3 & 0.76 \\
\hline SpO2 (1)-SpO2 (2) & 0.2 & 1.01 & 1.4 & 0.168 \\
\hline SpO2 (1)-SpO2 (3) & 0.22 & 0.932 & 1.669 & 0.102 \\
SpO2 (2)-SpO2 (3) & 0.02 & 0.979 & 0.144 & 0.886 \\
RR (1)-RR (2) & 0.6 & 1.719 & 0.247 & 0.806 \\
\hline RR (1)-RR (3) & 0.04 & 1.564 & 0.181 & 0.857 \\
RR (2)-RR (3) & -0.02 & 1.545 & -0.092 & 0.927 \\
\hline
\end{tabular}

$\mathrm{SD} \rightarrow$ Standard Deviation

$\mathrm{HR}(1) \rightarrow$ Heart Rate in $1^{\text {st }}$ reading;

HR (2) $\rightarrow$ Heart Rate in $2^{\text {nd }}$ reading;

HR $(3) \rightarrow$ Heart Rate in $3^{\text {rd }}$ reading

SBP (1) $\rightarrow$ Systolic Blood Pressure in $1^{\text {st }}$ reading;

SBP (2) Systolic Blood Pressure in $2^{\text {nd }}$ reading;

SBP (3) Systolic Blood Pressure in $3^{\text {rd }}$ reading

DBP (1) $\rightarrow$ Diastolic Blood Pressure in $1^{\text {st }}$ reading;

DBP (2) $\rightarrow$ Diastolic Blood Pressure in $2^{\text {nd }}$ reading;

DBP (3) $\rightarrow$ Diastolic Blood Pressure in $3^{\text {rd }}$ reading

$\mathrm{SpO}_{2} \rightarrow$ percentage saturation of hemoglobin with oxygen $\mathrm{SpO}_{2}(1) \rightarrow \mathrm{SpO}_{2}$ in $1^{\text {st }}$ reading;

$\mathrm{SpO}_{2}(2) \rightarrow \mathrm{SpO}_{2}$ in $2^{\text {nd }}$ reading; $\mathrm{SpO}_{2}(3) \rightarrow \mathrm{SpO}_{2}$ in $3^{\text {rd }}$ reading $\mathrm{RR}(1) \rightarrow$ Respiratory Rate in $1^{\text {st }}$ reading;

$\mathrm{RR}(2) \rightarrow$ Respiratory Rate in $2^{\text {nd }}$ reading; RR (3) $\rightarrow$ Respiratory Rate in $3^{\text {rd }}$ reading

Table 3: Comparing the difference in values of variables in baseline reading and after 6 months in between the two groups.

\begin{tabular}{lccccc}
\hline & Mean* & SD & t-value & Df & p-value \\
\hline HR E & 0.26 & 10.9 & 0 & 98 & 1 \\
HR NE & 0.26 & 10.9 & & & \\
SBP E & 2.96 & 10.3 & 0 & 98 & 1 \\
SBP NE & 2.96 & 10.3 & 0 & & \\
DBP E & -1.36 & 9.6 & 0 & 98 & 1 \\
DBP NE & -1.36 & 9.6 & & & \\
SpO2 E & 0.22 & 0.9 & 0.421 & 98 & 0.675 \\
SpO2 NE & 0.14 & 0.9 & & & \\
RR E & 0.04 & 1.56 & 0.226 & 98 & 0.822 \\
RR NE & -0.02 & 1.03 & & & \\
\hline
\end{tabular}

Mean $\rightarrow$ difference in baseline value and value after 6 months exposure $\mathrm{HRE} \rightarrow$ mean HR (1) - mean HR (3) of exposed group students $\mathrm{HR} N \mathrm{NE} \rightarrow$ mean HR (1) - mean HR (3) of non-exposed group of students SBP E $\rightarrow$ mean SBP (1) - mean SBP (3) of exposed group students SBP NE $\rightarrow$ mean SBP (1) - mean SBP (3) of non-exposed group students DBP E $\rightarrow$ mean DBP (1) - mean DBP (3) of exposed group students DBP NE $\rightarrow$ mean DBP (1) - mean DBP (3) of non-exposed group of students $\mathrm{SpO} 2 \mathrm{E} \rightarrow$ mean SpO2 (1) - mean SpO2 (3) of exposed group $\mathrm{SpO} 2 \mathrm{NE} \rightarrow$ mean SpO2 (1) - mean SpO2 (3) of non-exposed RR E $\rightarrow$ mean RR1 - mean RR3 of exposed group RR NE $\rightarrow$ mean RR1 - mean RR3 of non-exposed 
fall in HR in the consecutive readings, but it was not significant statistically as the $p$ value $>0.05$. On comparing the mean systolic blood pressure of the exposed group of students in table 2 and on comparing the difference in mean systolic blood pressure in baseline reading and after six months in between the two groups in table 3 , there was a gradual decrease in systolic blood pressure, but it was not statistically significant as $p$ value $>0.05$.

On analysing the mean diastolic blood pressure of the MBBS students in table 2, there was a gradual increase diastolic blood pressure after 1 month of formaldehyde exposure. But there was a decrease in diastolic blood pressure by 6 months of exposure, but it was still more than that of the pre-exposure reading. However, these changes were not significant statistically as $p$ value $>0.05$. And on comparing the difference in mean diastolic blood pressure in baseline reading and after six months among the two groups in table 3 , there was no significant change.

On considering the mean $\mathrm{SpO}_{2}$ values among the exposed group in table 2 and on comparing the difference in mean $\mathrm{SpO}_{2}$ reading and after six months among the two groups, there was a gradual decrease in $\mathrm{SpO}_{2}$ in the consecutive readings in table 3 , nevertheless it was not significant statistically as $p$ value $>0.05$.

On considering the mean respiratory rate values among the exposed group in table 2 , there was a decrease in respiratory after 1 month that reverted back towards baseline values by six months. And on comparing the difference in mean respiratory rate reading and after six months among the two groups in table 3 , there was a gradual decrease in respiratory rate in the exposed group, however it was not significant statistically as $p$ value $>0.05$.

\section{DISCUSSION}

Medical professionals are routinely exposed to formaldehyde occurs from various sources like from dissection hall in anatomy department, in pathology laboratory, sterilisation of theatres. Due to the toxic effect of formaldehyde and formaldehyde treated products, they are restricted in several European countries [4]. But in India we are still using formaldehyde extensively in medical profession. So, in this study aims to compare the effect of formaldehyde vapour on cardio-respiratory variables in medical students.

On comparing cardio-respiratory parameters which included heart rate, systolic blood pressure, diastolic blood pressure, percentage of hemoglobin saturation with oxygen $\left(\mathrm{SpO}_{2}\right)$ and respiratory rate, there was a decrease in heart rate, systolic blood pressure and $\mathrm{SpO}_{2}$ values and an increase in diastolic blood pressure and respiratory rate among the MBBS students but it was not significant statistically. But in a Indian study done by Neginhal $R$ et al recorded significant decrease in heart rate and diastolic blood pressure, but decrease in systolic blood pressure was not statistically significant in values recorded 24 hours after exposure to formaldehyde in gross anatomy laboratory among 50 first year medical students. [6].

Takeshita D studied the effect of formaldehyde intravenous infusion of $3.7 \%$ formaldehyde solution for 20-30 minutes on rat heart. There was significant decrease in left ventricular end-systolic pressure, heart rate and cardiac output per minute, which indicates an acute pump failure. Ultrastructural assessment revealed marked dilatation of sarcoplasmic reticulum. The cause for this dilatation and thereby acute pump failure was said to be impairment of $\mathrm{Ca}^{2+}$ handling in cardiac excitation-contraction coupling [7]. Strubelt $O$ et al also studied the effect of acute cardiovascular toxicity of formalin on anesthetized rats by artificial infusion of $0.01 \mathrm{ml}$ formalin $/ \mathrm{kg} / \mathrm{min}$. There was a sharp and immediate decline of systemic arterial blood pressure which was due to the direct vasodilatory action of formaldehyde on vascular smooth muscle. Also there was a cardio depressive effect as seen by decreased heart rate and atrial contractility [8]. Tani T and co-workers studied the effect of $10 \mathrm{ppm}$ formaldehyde inhalation on cardiovascular and respiratory systems in unanesthetized rabbits. There was inhibition of heart rate and respiratory movement due to reflex 
reaction during sensory irritation of upper respiratory tract which was sympathetically mediated and the bradycardia was due to inhibition of transmitter release from adrenergic nerve endings [9].

Studies based on these parameters for chronic exposure to formaldehyde on animals or humans are limited. So we can't comment on the chronic effects apart from the findings from the present study in which no statistically significant difference was noted for cardiorespiratory variables (heart rate, systolic blood pressure, diastolic blood pressure, $\mathrm{SpO}_{2}$ and respiratory rate) in pre-exposure and one \& six month after exposure values. The reason could be because of lower quantity of formalin exposure owing to the proper ventilation of the dissection hall as per the $\mathrm{MCl}$ regulations.

Limitation of study: Study could have been extended for a longer period and over a larger population could have been taken.

\section{CONCLUSION}

We concluded from our present study that following 6 months of exposure to formalin there was a fall in cardio-respiratory parameters. Chronic exposure to formaldehyde on animals or humans related studies are limited. So, Further studies should be done on these parameters to analyse the effects of formalin exposure on those parameters with large no of participants and longer duration of exposure.

\section{ACKNOWLEDGEMENT}

We are grateful to Dr.K.P.Kalyanikutty and Dr. Amar Jayanthi for their support and valuable recommendations. We are also grateful to Dr. Sudhiraj.T.S for his guidance with statistical analysis. We express our sincere thanks to all the participants in our study.

\section{REFERENCES}

[1]. Krishnaiah M, Murudula C. A study on the adverse effects of formaldehyde on the staff of anatomy departments working in various medical colleges. J Evol Med Dent Sci. 2012;1(4):559-64.

[2]. Rani KD, Alex L. Exposure to formaldehyde in the medical field and a review of its toxic effects. Pushpagiri Med J. 2011;2(2):124-30.

[3]. Wibowo A. Formaldehyde. Stockholm (Sweden): ARBETE OCH HÄLSA, National Institute for Working Life, 2003. 82p. Report No.: 131.

[4]. Uchiyama I.Toxicity of formaldehyde exposure and the details of its control measures. Kaibogaku Zasshi. 2010;85(1):29-34.

[5]. Shrivastava A, Saxena Y. Effect of formalin vapours on pulmonary functions of medical students in anatomy dissection hall over a period of one year. Indian J Physiol Pharmacol. 2013;57(3):255-60.

[6]. Neginhal R, Herur A, Chinagudi S, Rairam GB, Kolagi $\mathrm{S}$, Ambi U. Cardiorespiratory effects of acute exposure to formaldehyde in gross anatomy laboratory in medical students - a comparative study. 2013;2(1):32-5

[7]. Takeshita D, Nakajima-Takenaka C, Shimizu J, Hattori $H$, Nakashima T, Kikuta A, et al. Effects of formaldehyde on cardiovascular system in in-situ rat hearts. Basic Clin Pharmacol Toxicol. 2009;105(4):271-80.

[8]. Strubelt O, Brasch H, Pentz R, Younes M. Experimental studies on the acute cardiovascular toxicity of formalin and its antidotal treatment. Clin Toxicol. 1990;28(2):221-33.

[9]. Tani T, Kogi K, Horiguchi Y. Inhibitory effects of formaldehyde inhalation on the cardiovascular and respiratory systems in unanesthetized rabbits. Jap J Pharmacol. 1986;40(4):551-9.

How to cite this article: V Ravi Kumar, M.C. Sudhakaran, Ashwani Sharma, Shivakrishna Gouroju. Effect of Formaldehyde on Cardiorespiratory parameters in Medical students - An observational study. Int J Intg Med Sci 2021;8(2):971-975. DOI: 10.16965/ijims.2021.104 